\title{
Melting and freezing characteristics and structural properties of supported and unsupported gold nanoclusters
}

\author{
Chin-Lung Kuo and Paulette Clancy* \\ School of Chemical and Biomolecular Engineering \\ Cornell University \\ Ithaca, NY 14853 \\ Supporting Information
}

AUTHOR EMAIL ADDRESS: ck77@cornell.edu (C.-L. Kuo), pc@pcnet.cheme.cornell.edu (P. Clancy). 

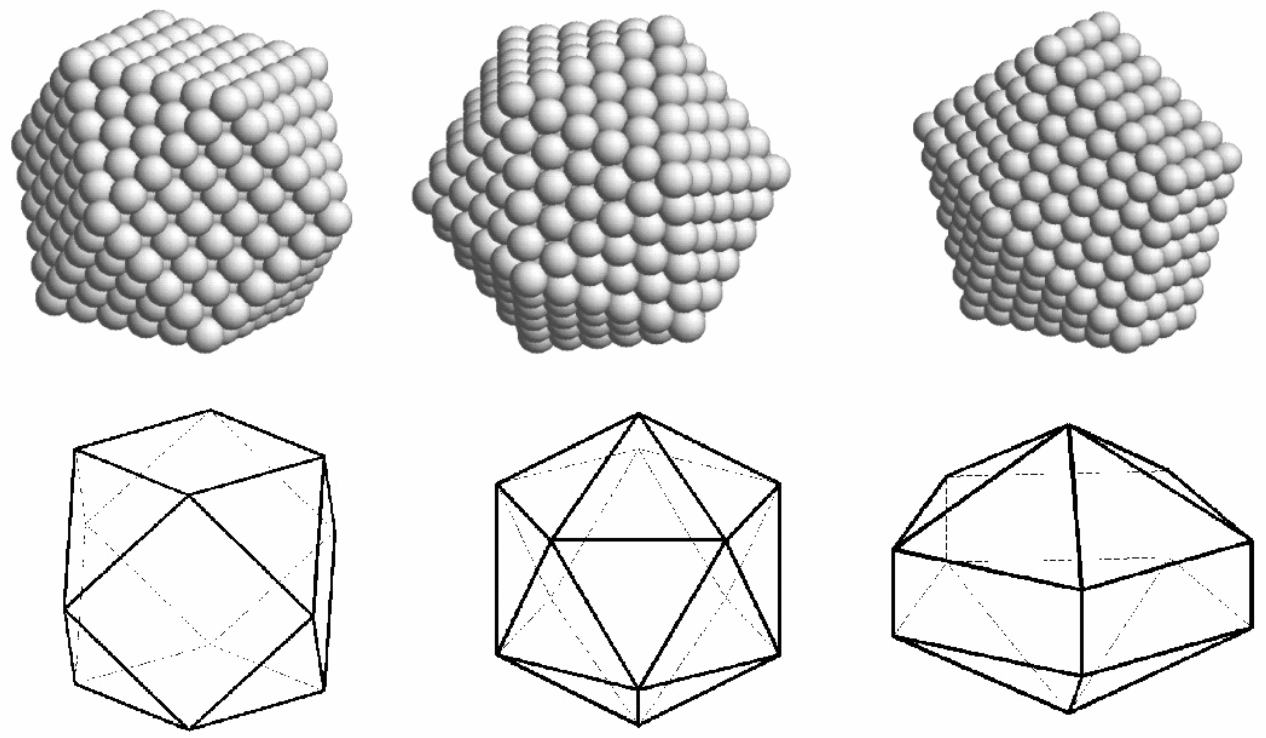

\section{Cuboctahedral Icosahedral Decahedral (fcc)}

Figure S1. The three most common structural motifs for metal clusters. 


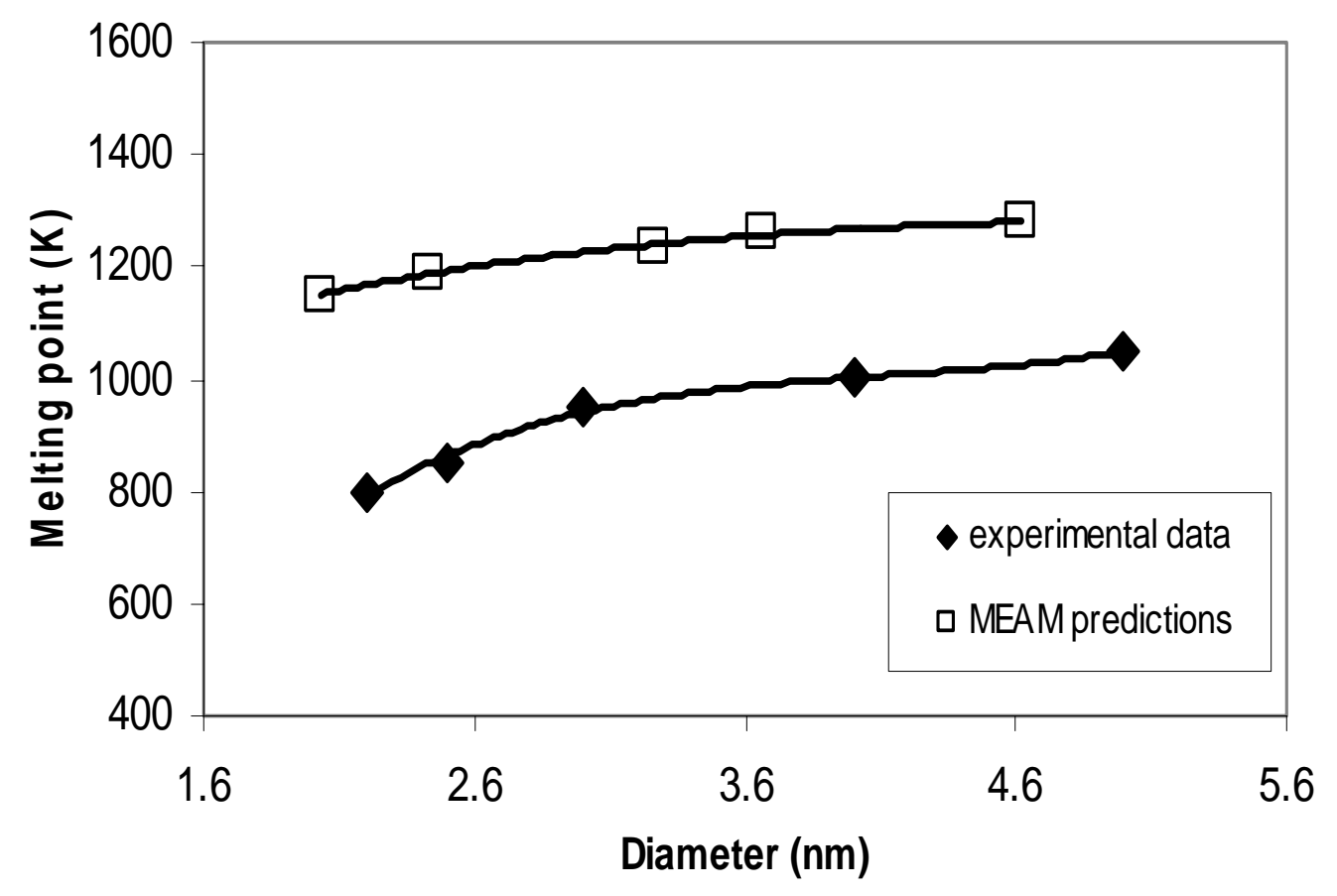

Figure S2. Comparison of the computed melting points of unsupported Au nanoclusters using MEAM with the experimental data in Ref.[58]. The experimental bulk melting point of gold is 1300K, while that of MEAM-modeled gold is $1500 \mathrm{~K}$, thus the depression of the melting points of clusters compared to the bulk are similar in both experiment and MEAM predictions. 


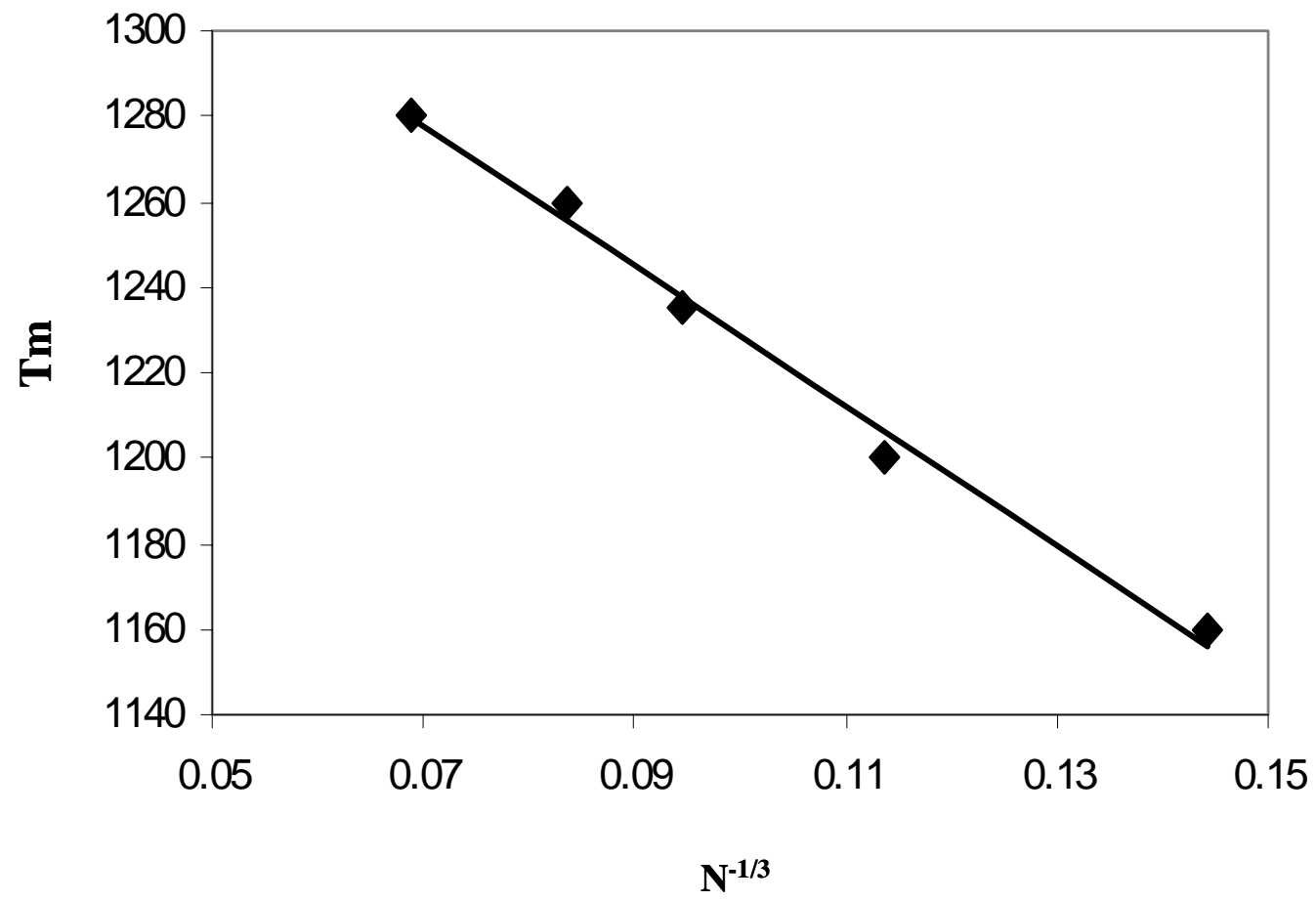

Figure S3. Computed melting points as a function of $\mathrm{N}^{-1 / 3}$. 


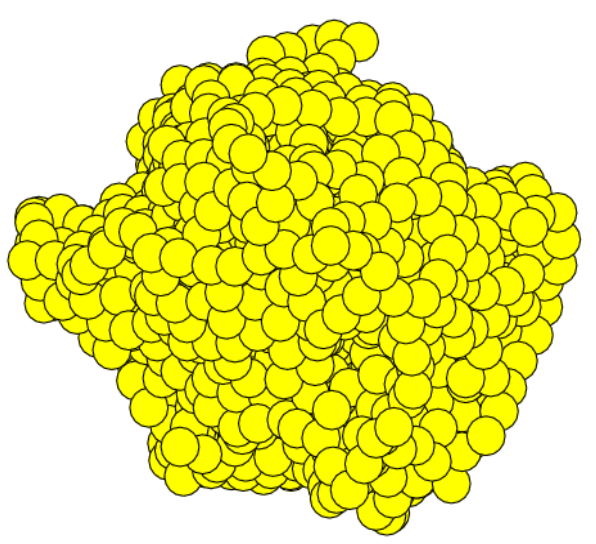

(a)

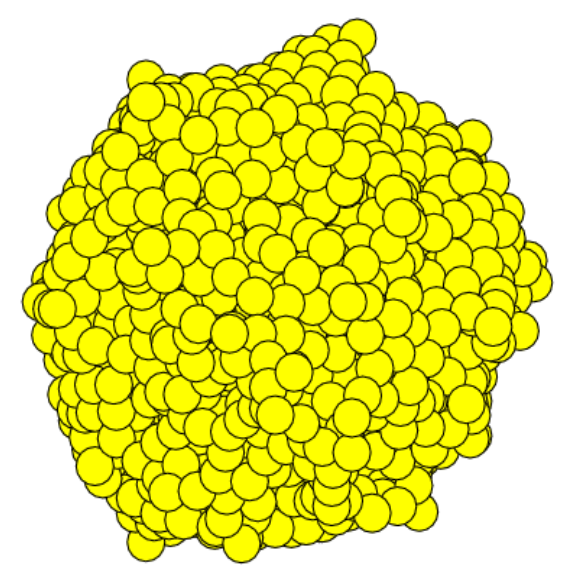

(c)

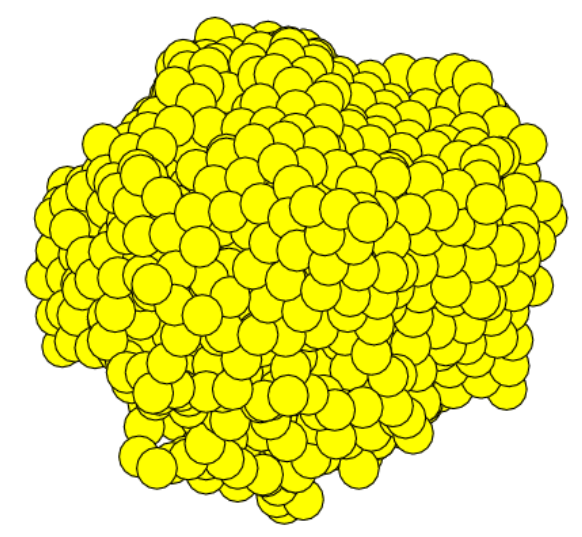

(b)

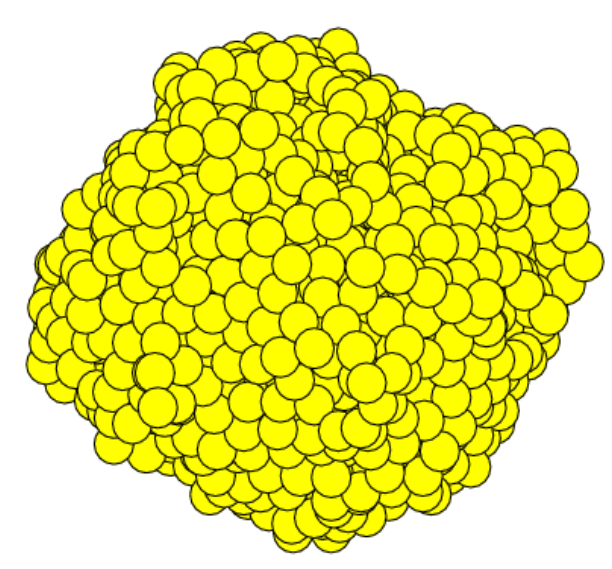

(d)

Figure S4. Snapshots of a $\mathrm{Au}_{1184}$ liquid cluster at $1300 \mathrm{~K}$, showing that the cluster was not always spherical but fluctuated rapidly between different shapes, resembling a combination of icosahedra, decahedra, and octahedra with disordered surfaces. In (a) and (b), the liquid cluster exhibited a decahedral shape; in (c), an icosahedral shape; in (d), an octahedral shape. 


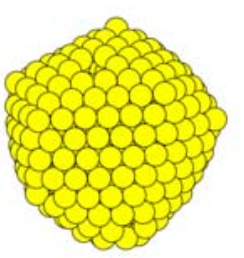

(a)

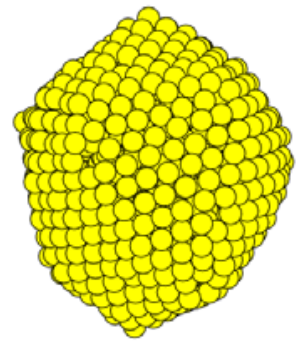

(b)

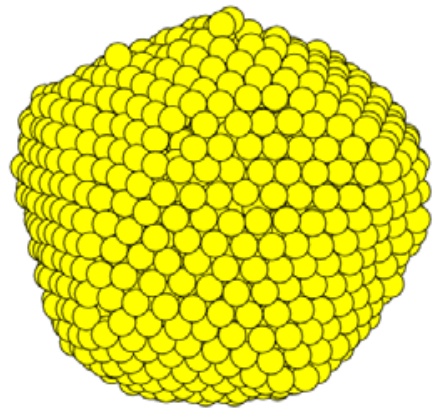

(c)

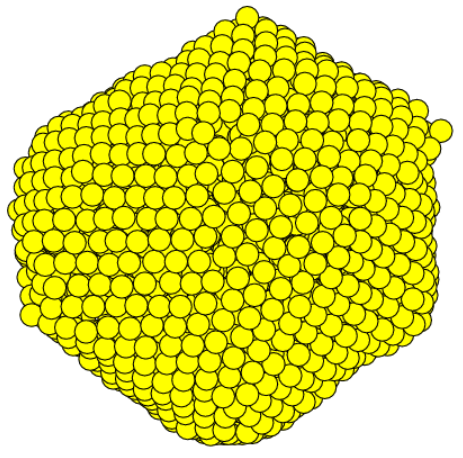

(d)

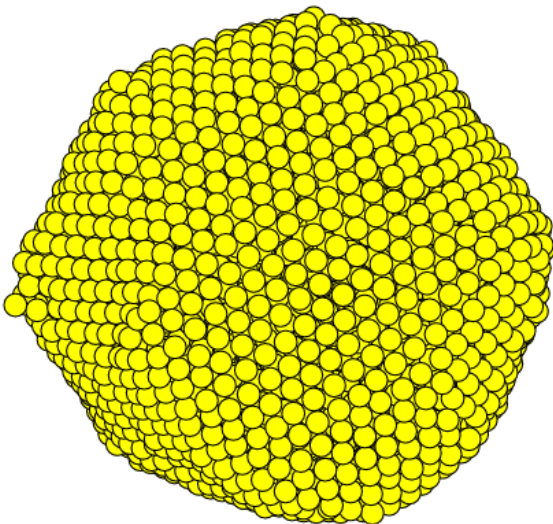

(e)

Figure S5. Configurations of $\mathrm{Au}_{333}, \mathrm{Au}_{682}, \mathrm{Au}_{1184}, \mathrm{Au}_{1713}$, and $\mathrm{Au}_{3055}$ clusters at $1000 \mathrm{~K}$ upon cooling, showing that they all froze into an icosahedral structure when the temperature was just below their freezing points. 

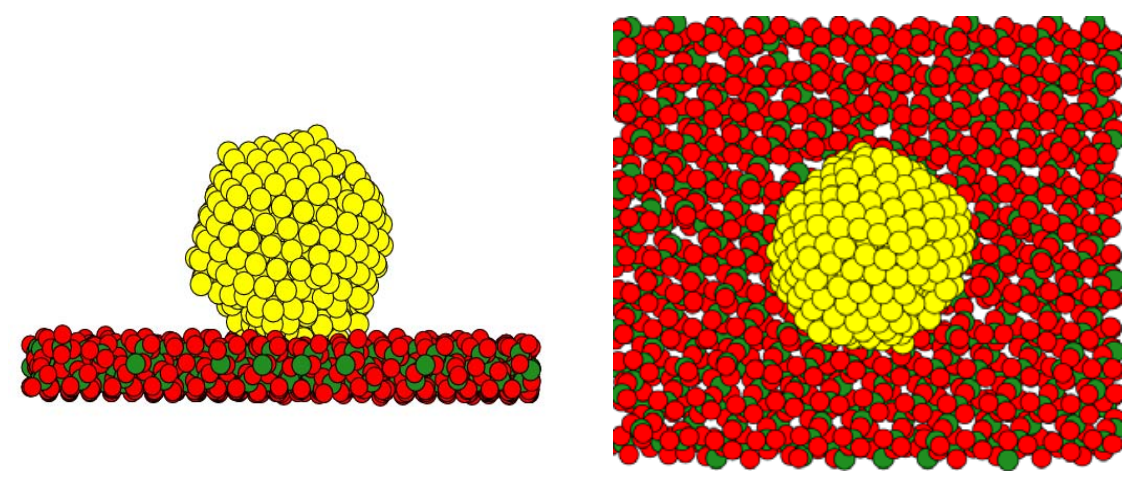

(a)
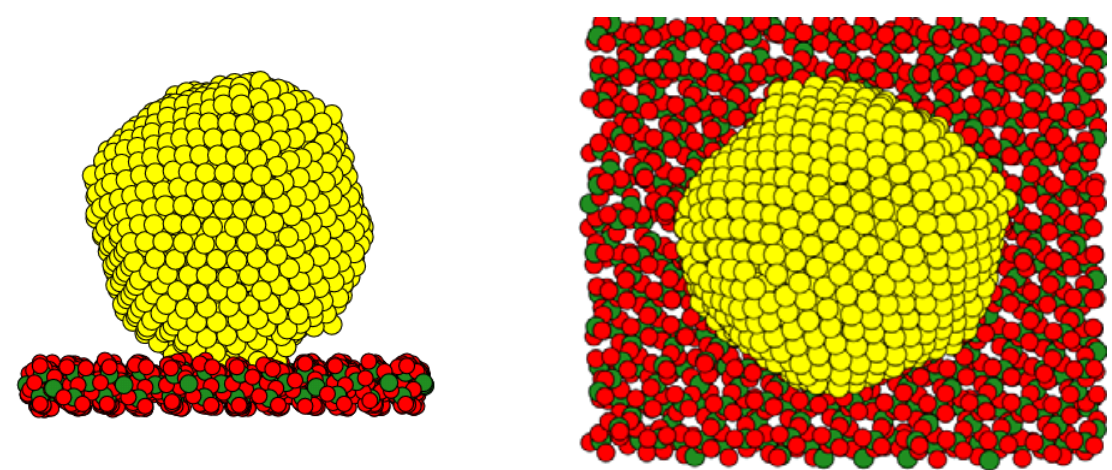

(b)
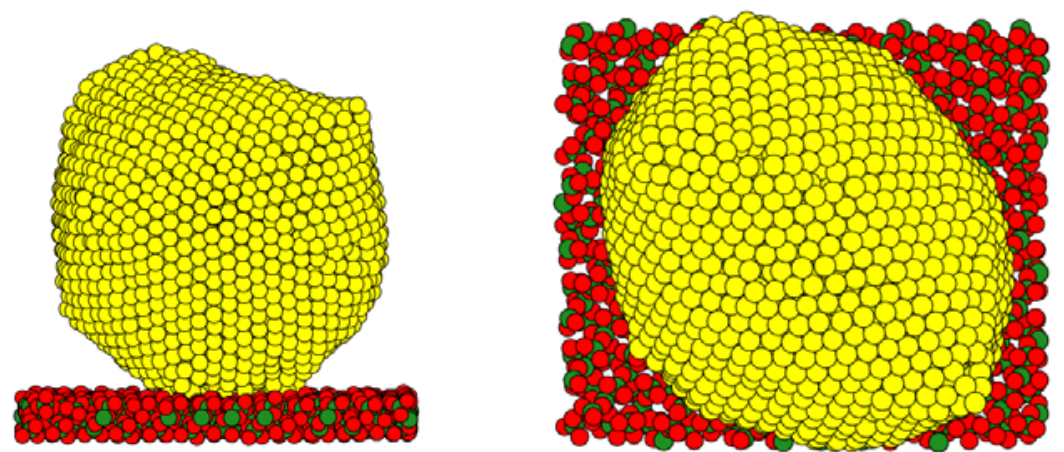

(c)

Figure S6. Snapshots of supported $\mathrm{Au}$ clusters (a) $\mathrm{Au}_{333}$, (b) $\mathrm{Au}_{1184}$, and (c) $\mathrm{Au}_{3055}$ at $1000 \mathrm{~K}$, showing that they all transformed into icosahedral structures at high temperatures, but were slightly deformed due to the strain at the gold-silica interface. 


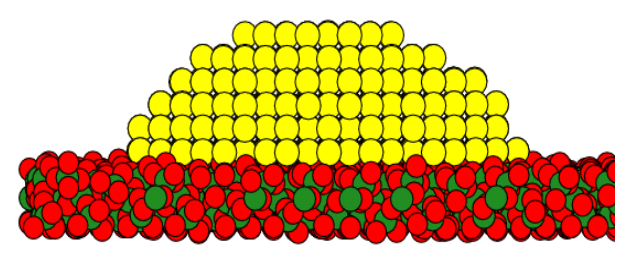

(a)

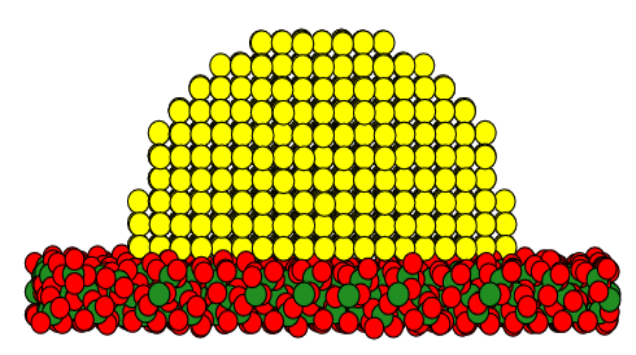

(c)

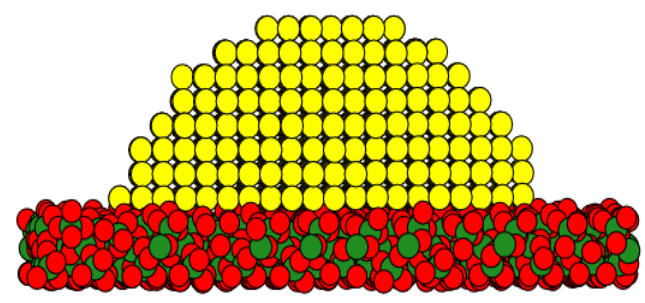

(b)

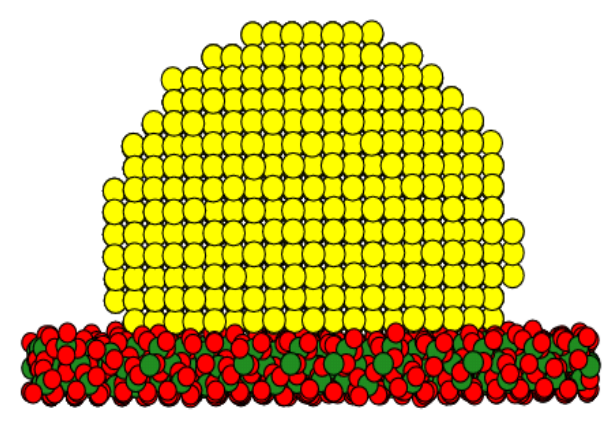

(d)

Figure S7. Initial configurations of (a) $\mathrm{Au}_{565}$, (b) $\mathrm{Au}_{786}$, (c) $\mathrm{Au}_{965}$, and (d) $\mathrm{Au}_{1758}$ clusters, chosen to be approximately a domed shape with local FCC order. 


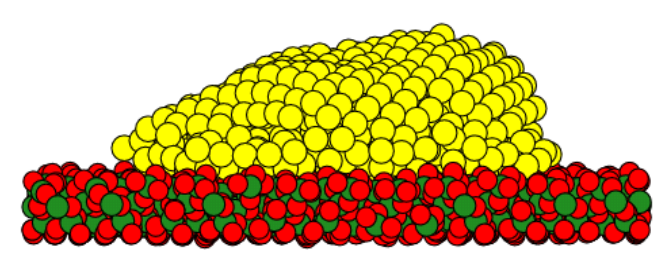

(a)

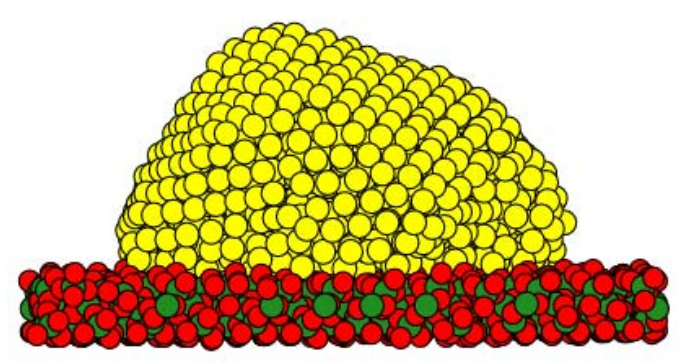

(c)

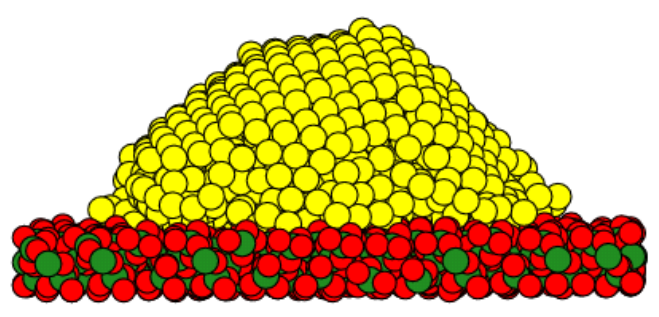

(b)

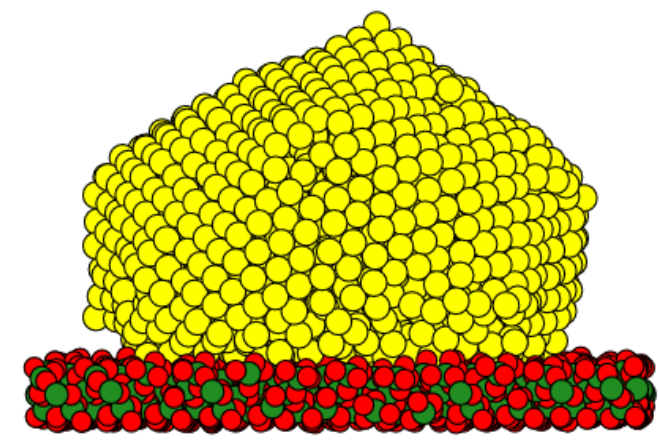

(d)

Figure S8. Side views of (a) $\mathrm{Au}_{565}$, (b) $\mathrm{Au}_{786}$, (c) $\mathrm{Au}_{965}$, and (d) $\mathrm{Au}_{1758}$ clusters at $1100 \mathrm{~K}$ upon cooling from the liquid phase. 


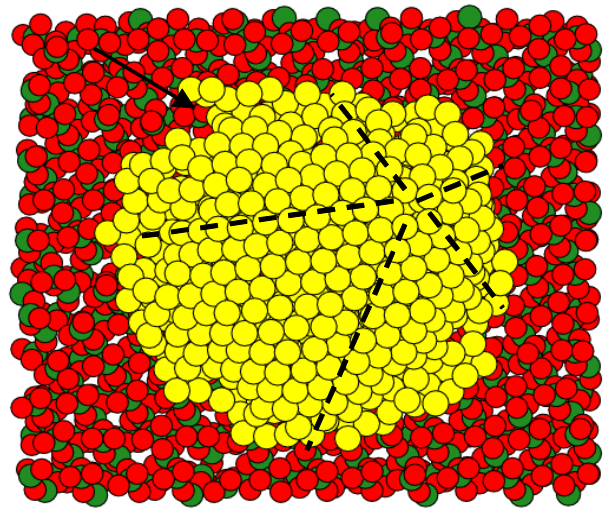

(a)

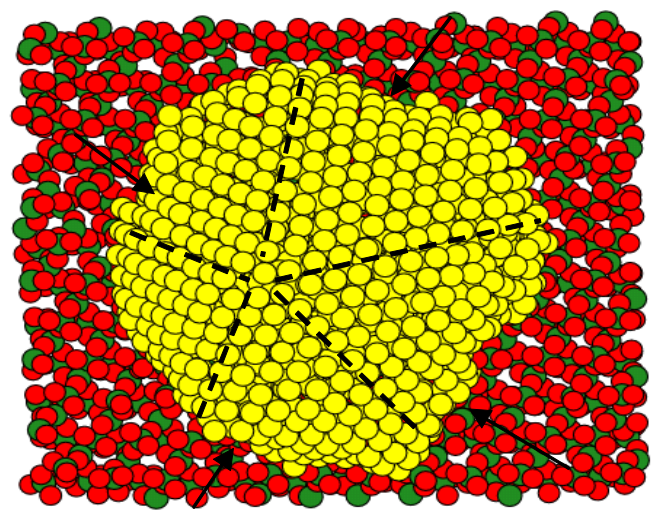

(c)

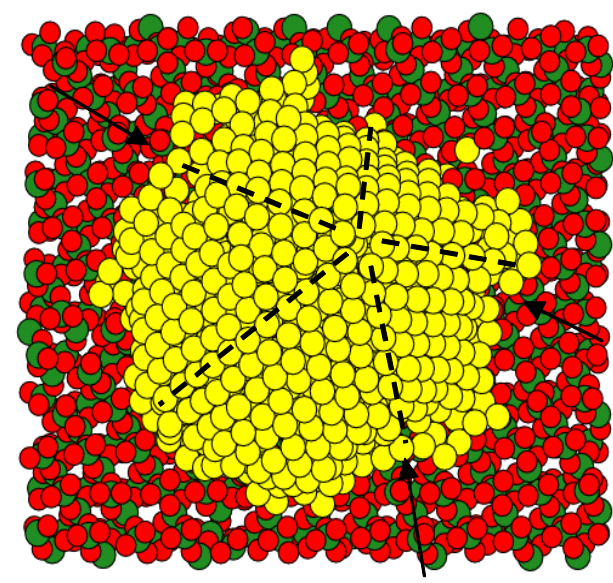

(b)

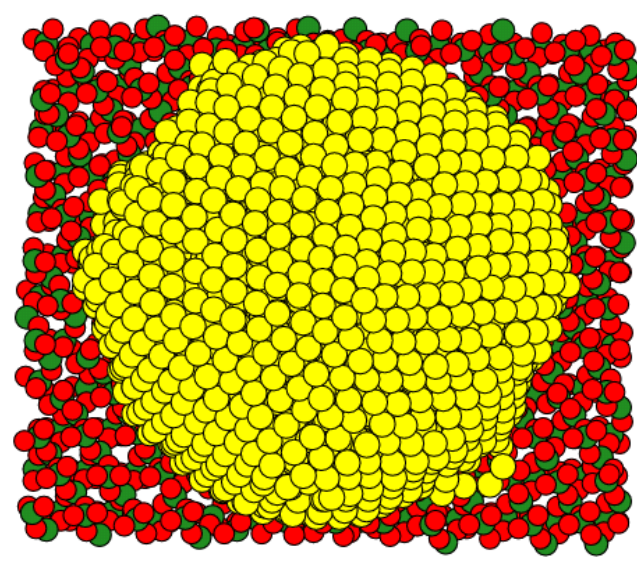

(d)

Figure S9. Top views of (a) $\mathrm{Au}_{565}$, (b) $\mathrm{Au}_{786}$, (c) $\mathrm{Au}_{965}$, and (d) $\mathrm{Au}_{1758}$ clusters at $1100 \mathrm{~K}$ upon cooling from the liquid phase. The re-entrant facets are indicated by the arrows. 

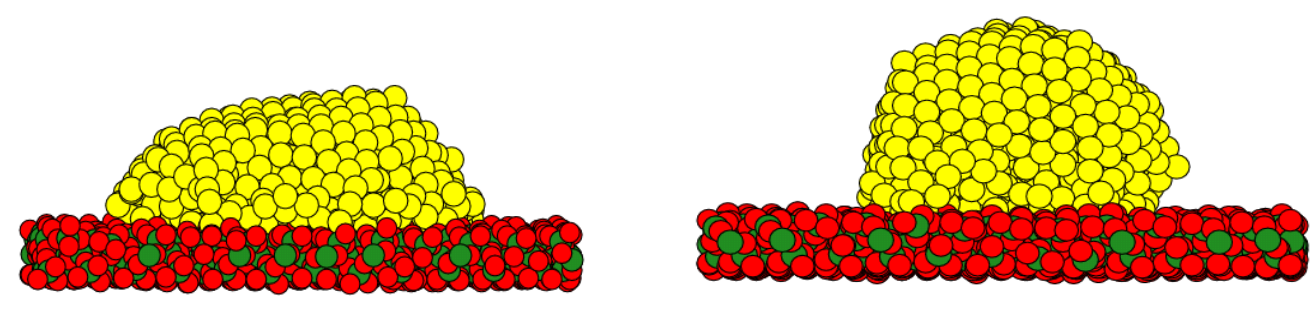

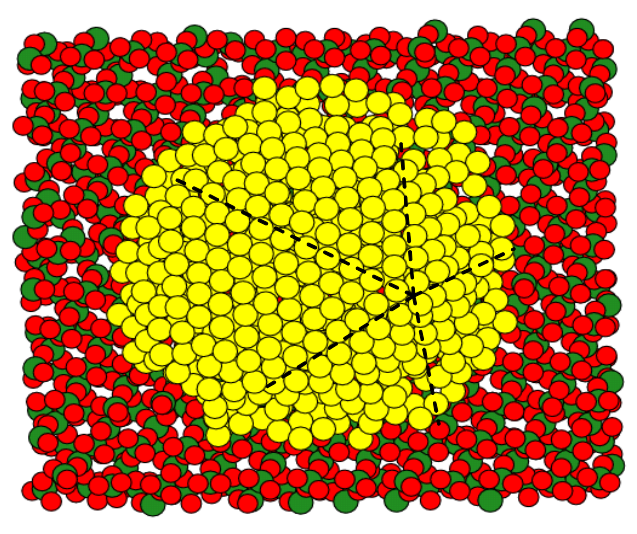

(a)

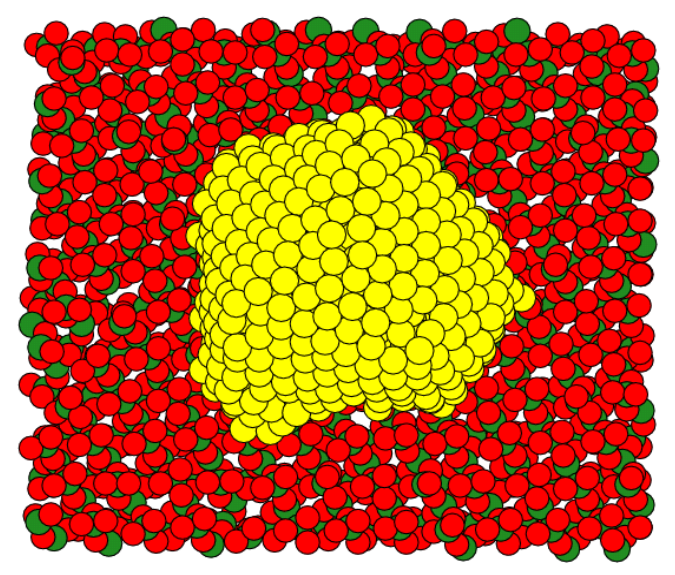

(b)

Figure S10. Comparison between $\mathrm{Au}_{565}$ and $\mathrm{Au}_{576}$ clusters, which have comparable sizes but different contact areas with the substrate. 

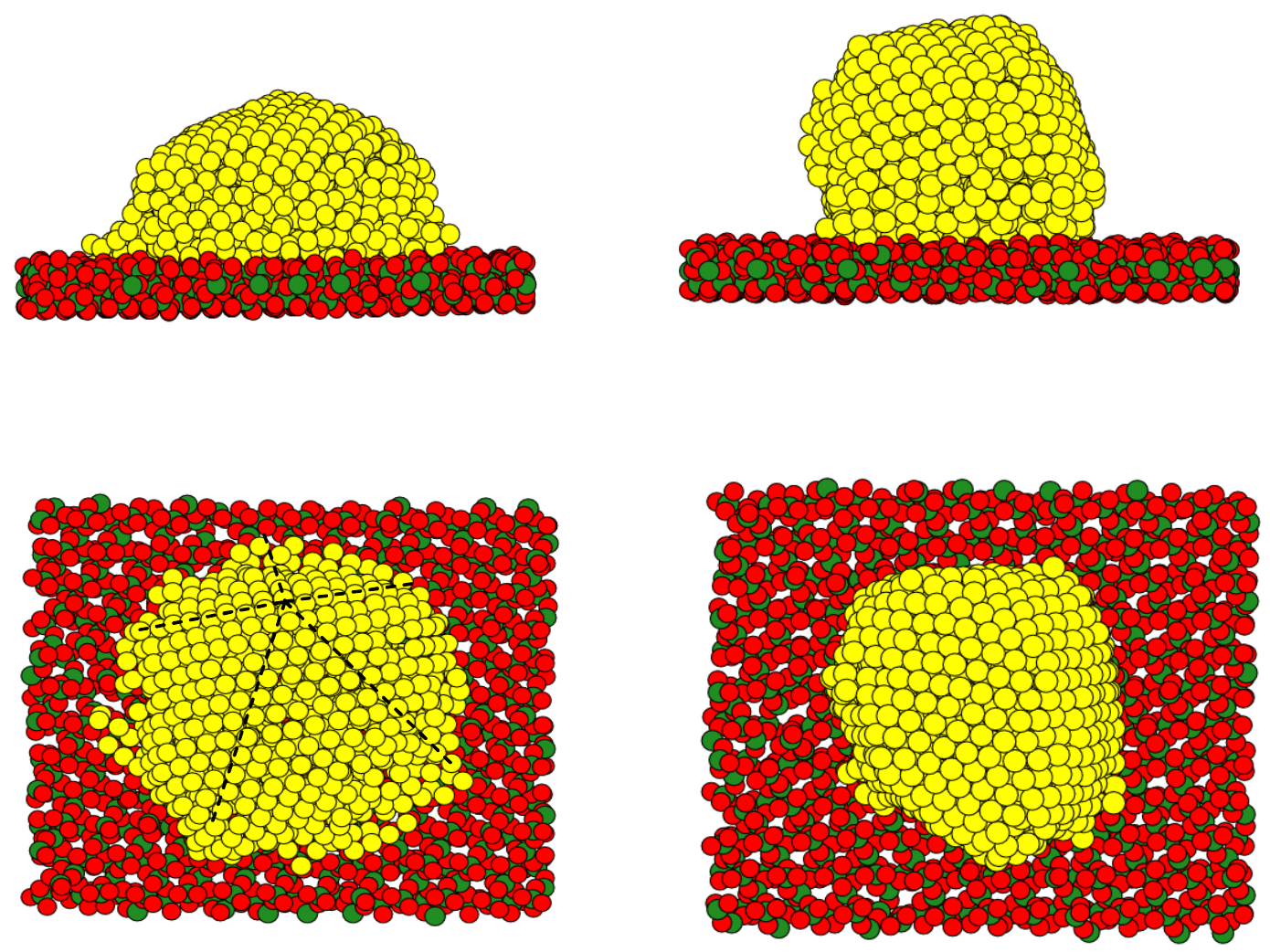

(a)

(b)

Figure S11. Comparison between $\mathrm{Au}_{786}$ and $\mathrm{Au}_{792}$ clusters, which have comparable sizes but different contact areas with the substrate. 

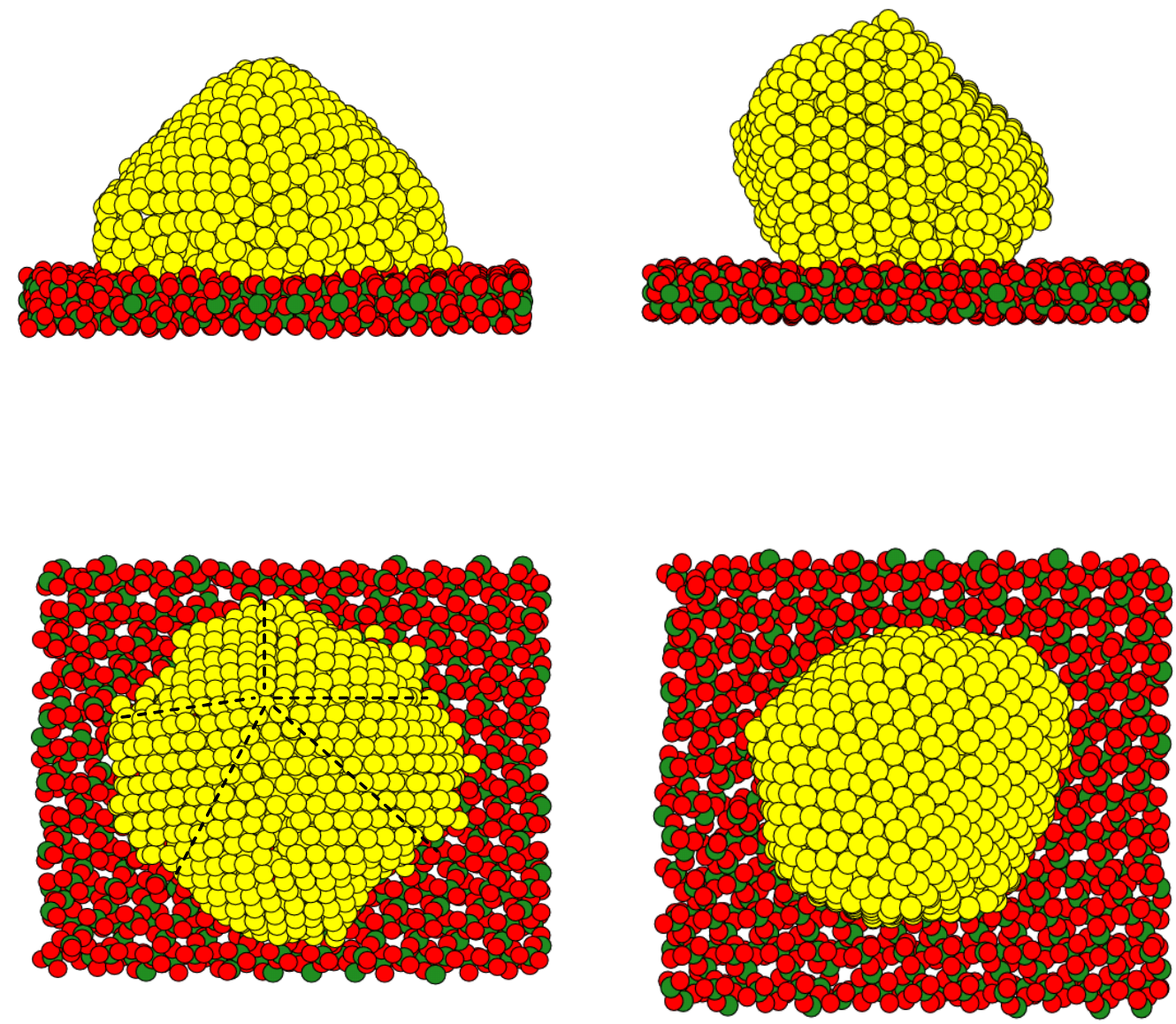

(a)

(b)

Figure S12. Comparison between $\mathrm{Au}_{965}$ and $\mathrm{Au}_{936}$ clusters, which have comparable sizes but different contact areas with the substrate. 

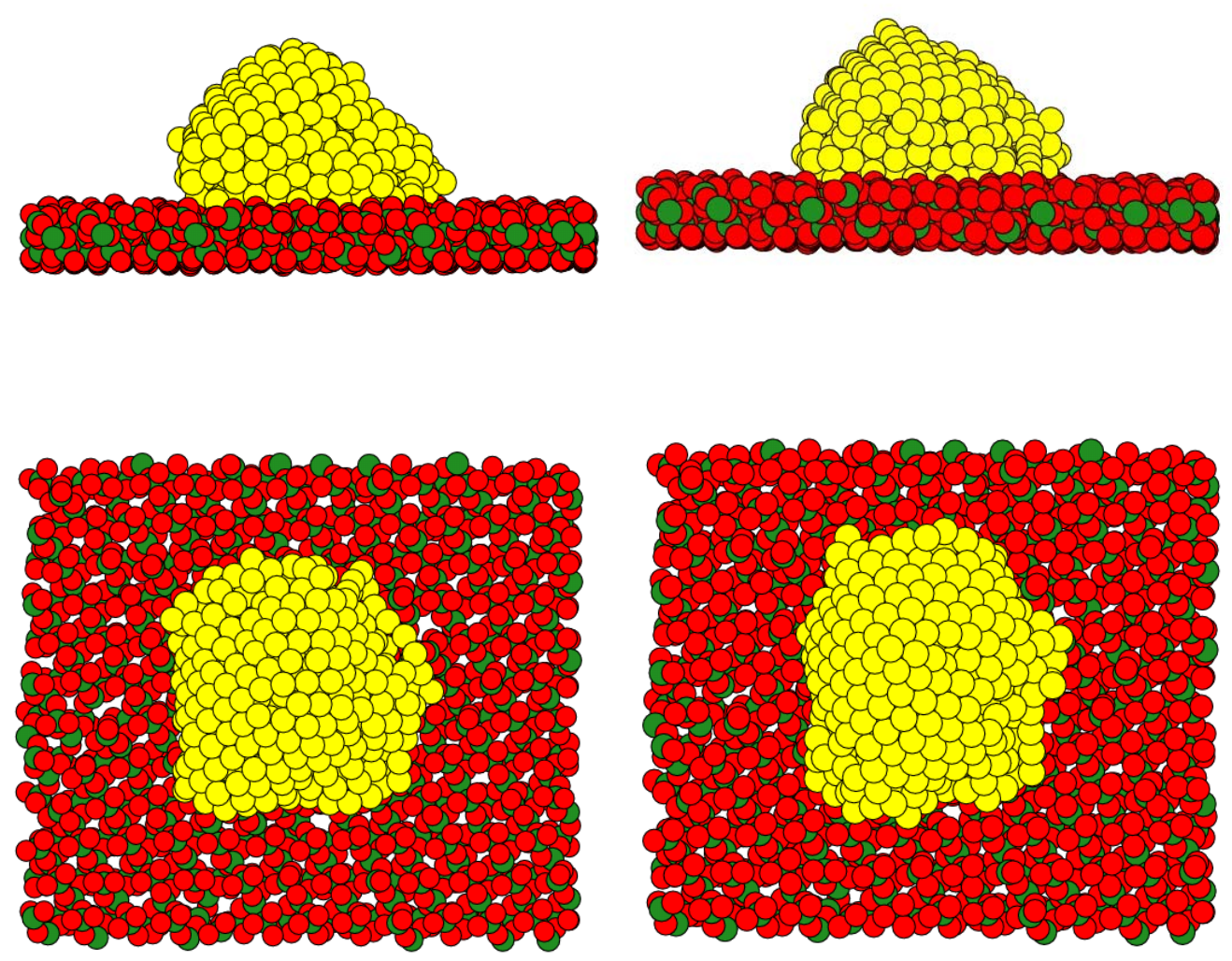

Figure S13. (a) The configuration of $\mathrm{Au}_{360}$ at $1100 \mathrm{~K}$ during heating; (b) the configuration of $\mathrm{Au}_{360}$ at $1100 \mathrm{~K}$ during cooling. 

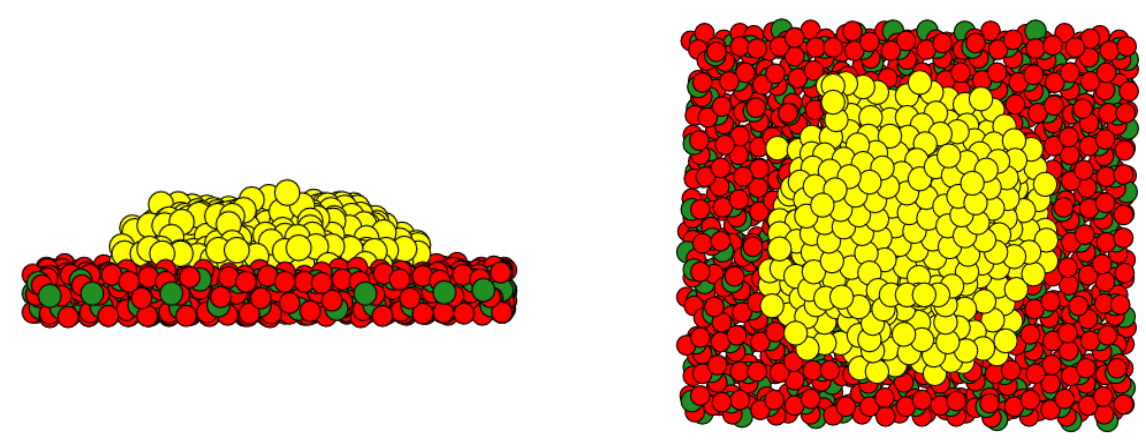

(a)
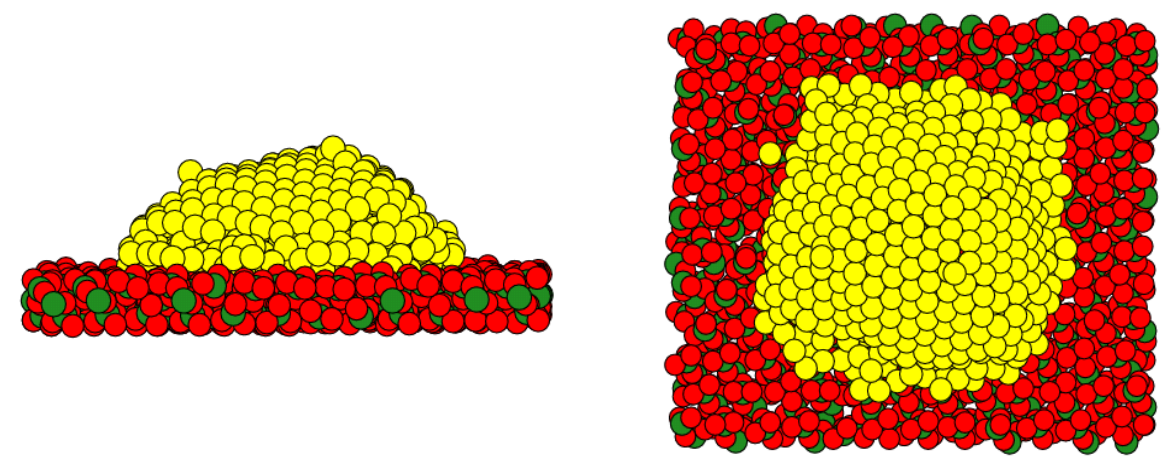

(b)
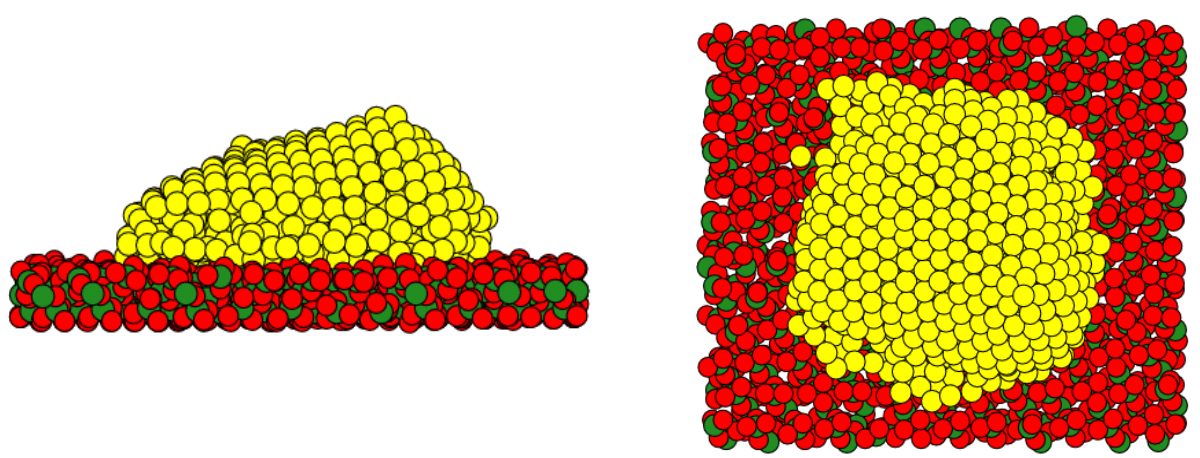

(c)

Figure S14. Snapshots of a Au island at the early stages during the growth. (a) $\mathrm{Au}_{402}$; (b) $\mathrm{Au}_{536}$; (c) $\mathrm{Au}_{600}$. 

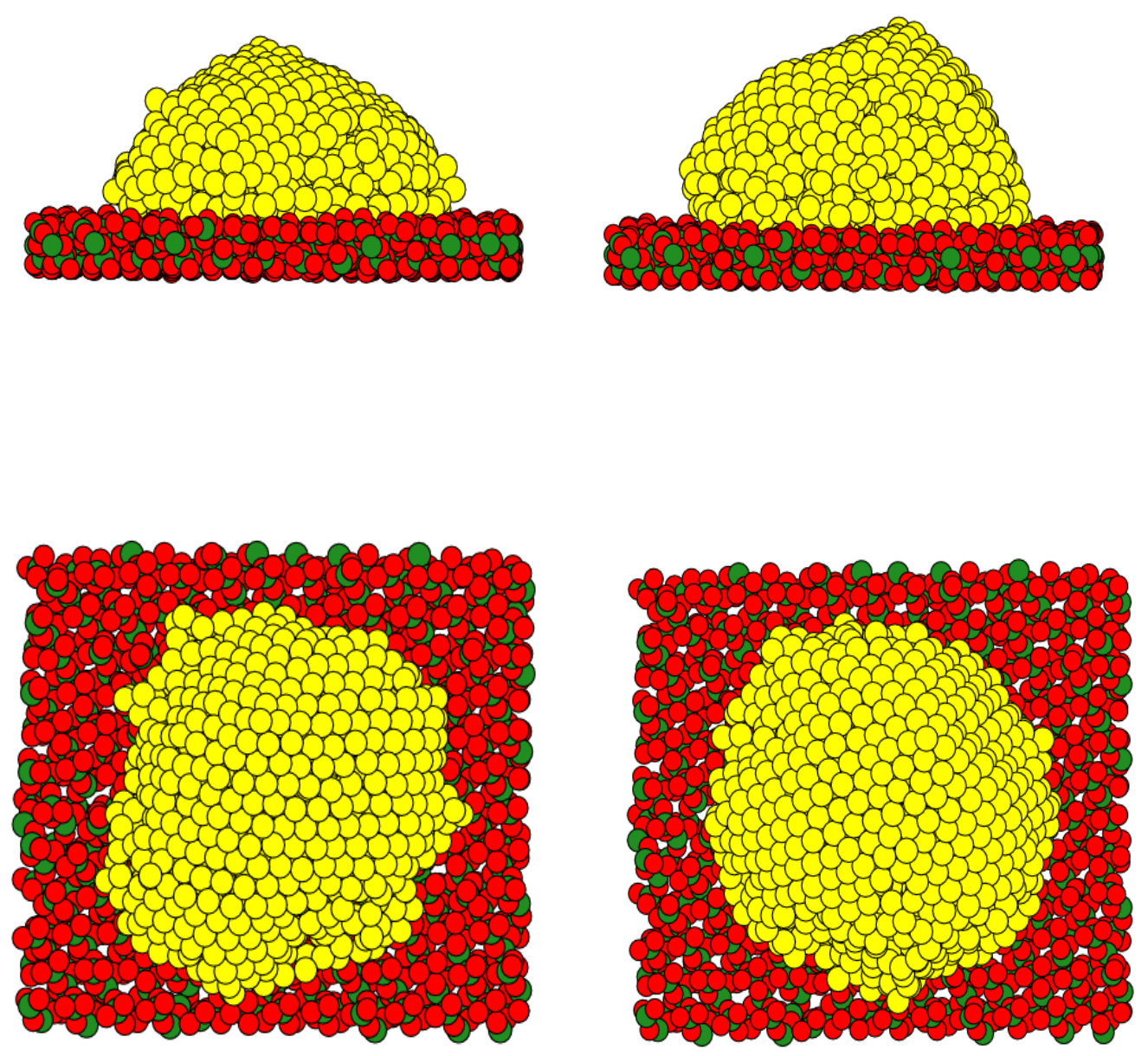

(a)

(b)

Figure S15. Snapshots of a Au island at the middle stage during the growth. (a) $\mathrm{Au}_{830}$; (b) $\mathrm{Au}_{945}$. 

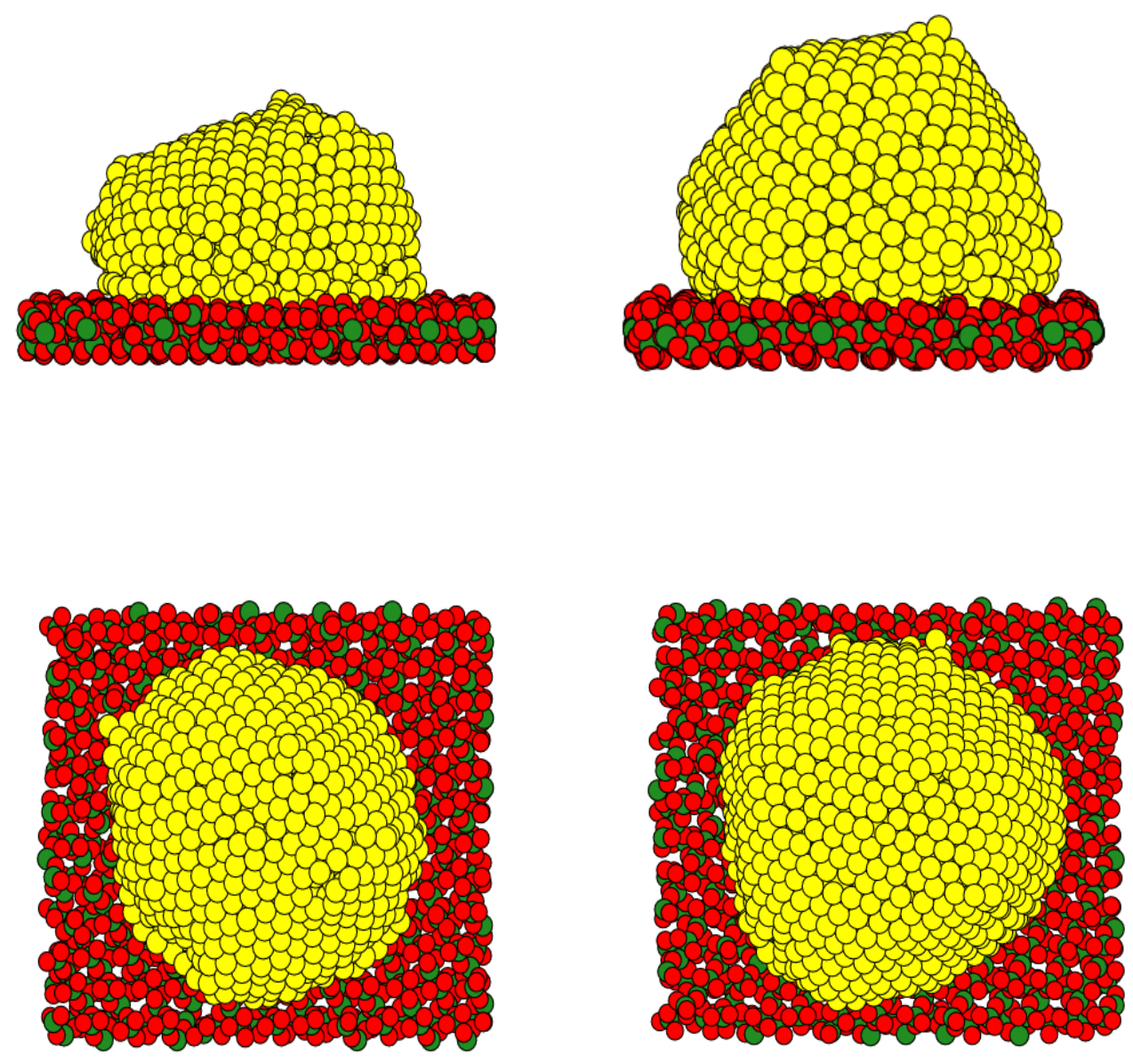

(a)

(b)

Figure S16. Snapshots of a Au island at the final stage during the growth.(a) $\mathrm{Au}_{985}$; (b) $\mathrm{Au}_{1345}$. 

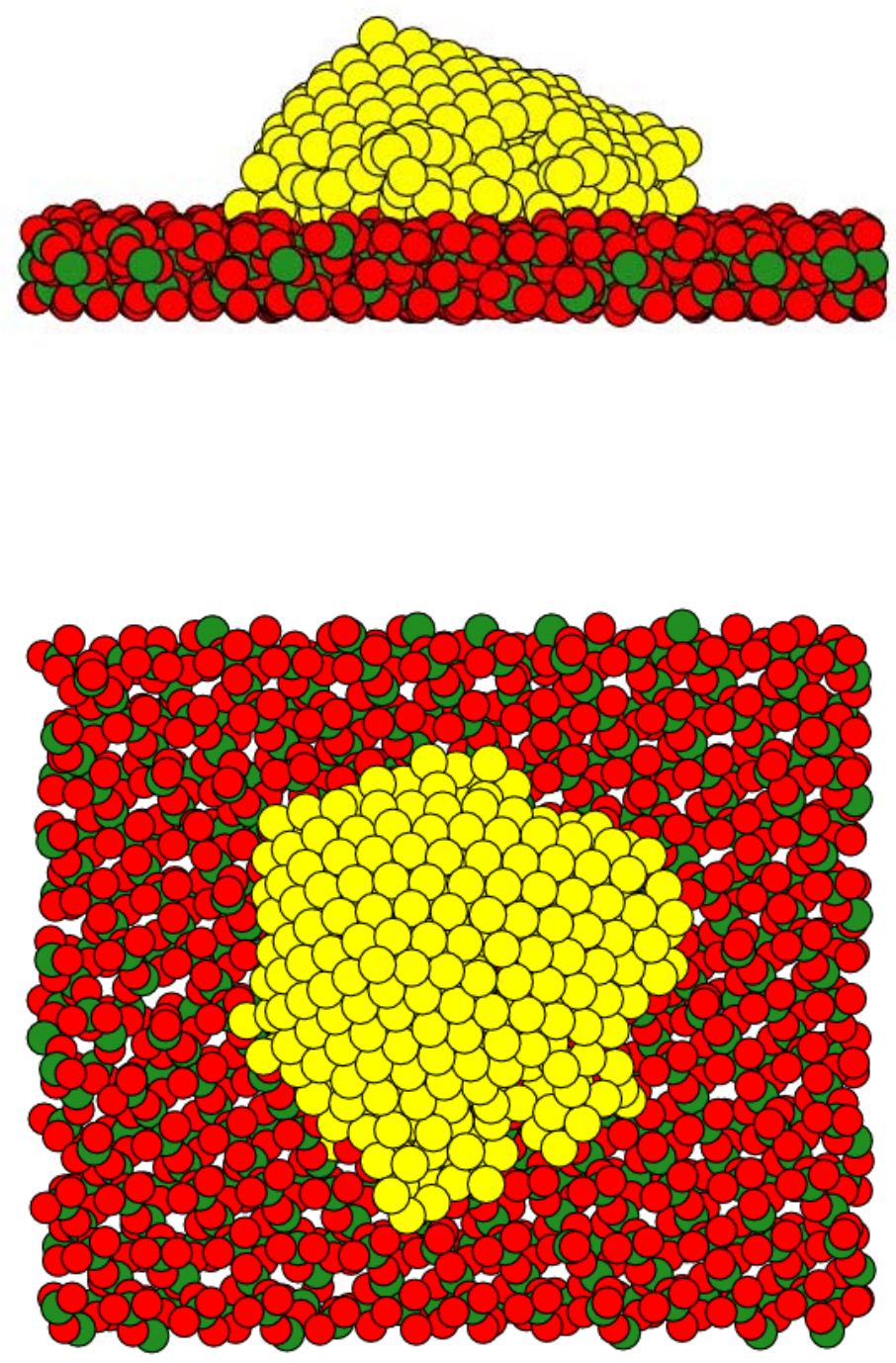

Figure S17. Snapshots of a Au island with a diameter of $2.4 \mathrm{~nm}$, showing that a decahedron has already formed as the number of $\mathrm{Au}$ atoms reached 320. 


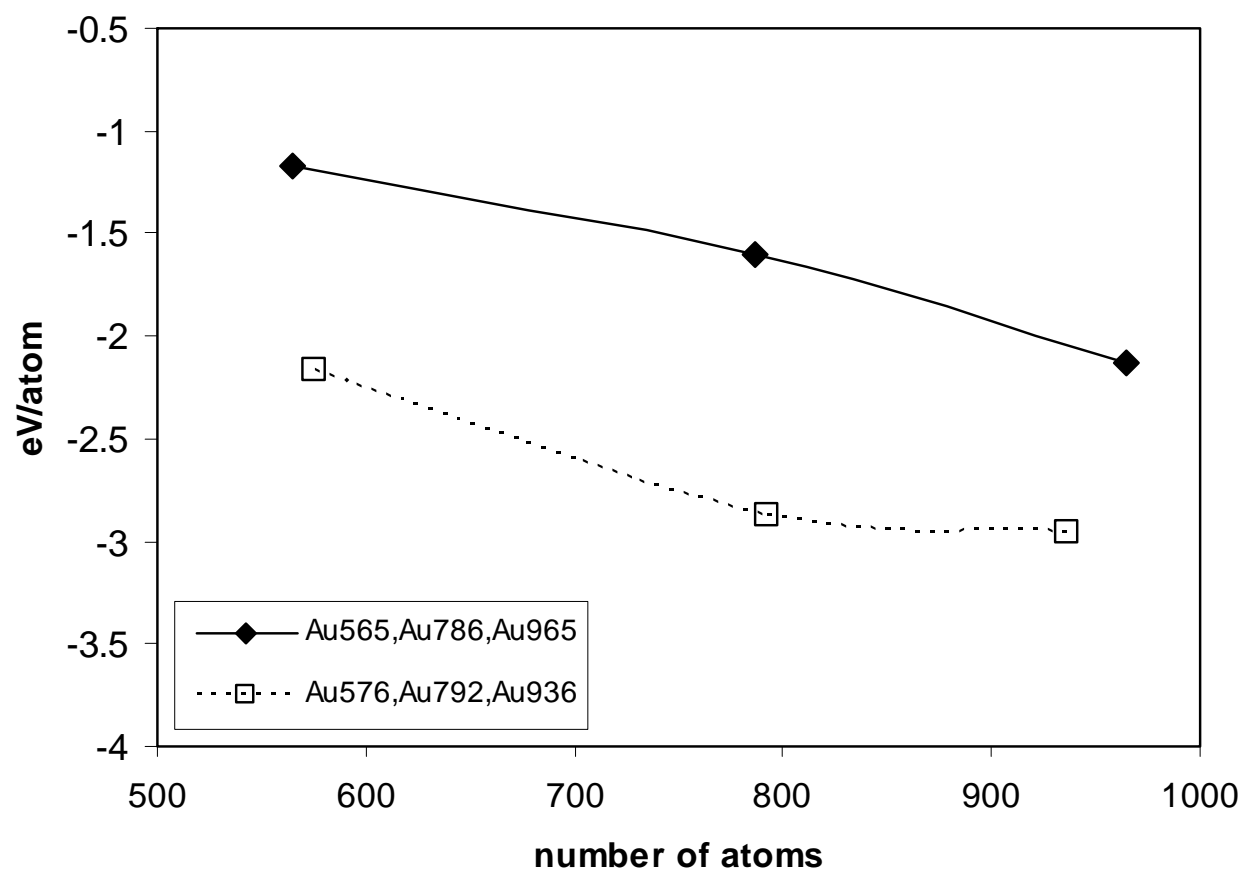

Figure S18. Comparison of the potential energies for $\mathrm{Au}_{576}, \mathrm{Au}_{792}$, and $\mathrm{Au}_{936}$ clusters to those for $\mathrm{Au}_{565}$, $\mathrm{Au}_{786}$, and $\mathrm{Au}_{965}$ clusters. 